\title{
Adesão aos Novos Mercados da BOVESPA: Novo Mercado, Nível 1 e Nível 2- Determinantes e Conseqüências
}

\author{
Jairo Laser Procianoy* \\ Rodrigo S. Verdi**
}

\section{Resumo}

Este artigo estuda os determinantes e as consequiências da adesão de empresas brasileiras aos novos mercados da BOVESPA: Novo Mercado, Nível 1 e Nível 2. Desde 2001 mais de 61 empresas passaram a serem transacionadas nestes mercados com o objetivo de adotar maiores níveis de disclosure e de governança corporativa. Entre os determinantes, encontrou-se que empresas de maior porte, mais lucrativas, negociadas em mercado estrangeiro (ADRs), e com menor concentração de acionista no controle acionário tem maior probabilidade de aderir os novos mercados. No que diz respeito às consequências, encontrouse que as empresas que aderiram os novos mercados apresentam maiores níveis de liquidez que empresas transacionadas no mercado tradicional da BOVESPA. Além disso, as empresas que aderiram ao Nível 2 e ao Novo Mercado (mercados com maiores requerimentos de disclosure e de governança) experimentaram um aumento de liquidez em relação ao nível de liquidez anterior a adesão.

Palavras-chave: governança corporativa; disclosure; niveis da Bovespa; ADRs.

Códigos JEL: G34; G14; G18.

\section{Abstract}

This paper studies the determinants and consequences of firms that adopted the Brazilian new stock exchanges - Novo Mercado, Nível 1 and Nível 2. Since 2001 more than 61 companies chose to be traded in these exchanges with the intention to raise their levels of disclosure and corporate governance. In terms of determinants, firms that adopted the new markets are larger, more profitable, more likely to be traded as ADRs and have more dispersed ownership. As for the consequences, shares of firms that adopted the new markets are more liquid than shares of firms traded in the regular exchange (BOVESPA). In addition, firms that adopted the Nível 2 and the Novo Mercado - markets with stricter disclosure and governance requirements - also experienced an increase in liquidity when compared to their liquidity prior to the adoption.

Submetido em Julho de 2007. Aceito em Fevereiro de 2009. O artigo foi avaliado segundo o processo de duplo anonimato além se de ser avaliado pelo editor. Editor responsável: Ricardo Leal. Os autores agradecem os comentários do Revisor anônimo, do Editor Ricardo Leal e o suporte financeiro do CNPq (Procianoy) e da Sloan School of Management (Verdi). Além disso, reconhece-se o excelente trabalho de suporte de pesquisa de Fernando Comiram na coleta dos dados e das informações necessárias.

*PPGA/EA/UFRGS. Av. Carlos Gomes, 1111 - Apto 1201, Porto Alegre - RS, CEP: 90.480-004. E-mail: jlprocianoy@ea.ufrgs.br

**Sloan School of Management, MIT. E-mail: rverdi@mit.edu 
Keywords: corporate governance; disclosure; BOVESPA markets; ADRs.

\section{Introdução}

Uma crescente literatura em finanças estuda os determinantes e as consequências da decisão de listar-se em novos mercados (Karolyi, 2003). Além disso, a literatura de contabilidade estuda os determinantes da decisão de adotar maiores níveis de disclosure (Leuz e Verrecchia, 2000, Verrecchia, 2001). Em geral, essa literatura conclui que o maior benefício desta decisão é a possibilidade de se obterem fundos a valores mais reduzidos que nos mercados de origem e de aumentarem a liquidez das ações da companhia. No entanto, para que se obtenham estes benefícios, é necessário que a empresa busque maiores níveis de governança e de disclosure de suas informações - os maiores requisitos de alguns destes novos mercados.

Este artigo estuda os determinantes e as conseqüências da adesão de empresas brasileiras aos diferentes níveis de listagem da BOVESPA: Novo Mercado, Nível 1 e Nível 2. O mercado brasileiro proporciona uma excelente oportunidade de testar estas hipóteses. Durante o período de 2001 a 2005, mais de 61 empresas brasileiras tomaram a decisão de listar-se nos novos mercados da BOVESPA. Implantados em dezembro de 2000 pela Bolsa de Valores de São Paulo - BOVESPA, os Níveis Diferenciados de Governança Corporativa são segmentos especiais de listagem que foram desenvolvidos com o objetivo de proporcionar um ambiente de negociação que estimulasse, simultaneamente, o interesse dos investidores e a valorização das companhias. Portanto, ao listar-se em um dos novos mercados da BOVESPA, a empresa compromete-se a um melhor nível de disclosure e de governança corporativa.

Este cenário é semelhante ao de uma empresa que decide lançar ADR (por exemplo, ver Hail e Leuz (2006)). Porém, do ponto de vista de pesquisa, ao se examinar os efeitos da adesão junto à BOVESPA, estes eventuais benefícios estão isolados de outros fatores que dificultam as conclusões quando olhamos os estudos de ADR, tais como um maior nível de monitoramento por parte da Security Exchange Commission - SEC e de investidores internacionais. É importante lembrar que para o mesmo ambiente institucional e legal temos diversos níveis de listagens e obrigações conseqüentes o que nos permite vislumbrar de forma clara as diferenças entre as diversas exigências de disclosure e de governança corporativa. Dessa forma, o mercado brasileiro caracteriza-se por um cenário ideal para estudar os determinantes da decisão de uma empresa em aumentar o seu nível de disclosure e de governança e, principalmente, estudar as conseqüências dessa decisão em relação à liquidez de suas ações negociadas.

O primeiro objetivo do estudo é estudar os determinantes e as características das empresas que aderiram aos novos mercados da BOVESPA. Dessa forma, busca-se melhorar o entendimento dos incentivos das empresas que aderiram a novos mercados e, como conseqüência, voluntariamente aumentam os seus níveis de disclosure e de governança. Alguns autores estudaram os determinantes dos níveis 
de disclosure e de governança das empresas (e.g., Leuz e Verrecchia (2000) e Doidge et al. (2004) no exterior e Barros e Fama (2004) e Silveira, Leal, Carvalhalda-Silva e Barros (2007) no Brasil) e encontraram que estes são função do tamanho da empresa, da necessidade de investimento e crescimento, da concentração acionária, da negociação em outros mercados e da estrutura de capital (esta literatura é revisada na seção 2).

Neste artigo encontrou-se, coerente com a literatura nesta área, evidência de que a adesão aos novos mercados da BOVESPA é influenciada pelo tamanho, lucratividade, dispersão acionária e a existência de ADR na empresa. Uma interpretação destes resultados consistente com os resultados em Leuz e Verrecchia (2000) é que empresas com grandes dispersões acionárias e transacionadas no exterior (isto é, empresas com maior informação assimétrica entre seus investidores) utilizam a adesão aos novos mercados como maneira de desmonstrar seu compromisso com uma política de transparência contábil e boa governança corporativa. No entanto, não confirmando a literatura, o efeito do endividamento e do crescimento das vendas em poucas vezes apresentou significância estatística. Além disso, não se encontrou evidência da influência do crescimento do patrimônio líquido na probabilidade de adesão aos novos mercados. Estes resultados contribuem para a literatura ao melhorar o entendimento dos determinantes de níveis de disclosure e de governança no mercado brasileiro.

O segundo objetivo do estudo é estudar as conseqüências da adesão aos novos mercados do ponto de vista da liquidez. Diversas teorias prevêem que a adoção de altos níveis de governança e de disclosure deveria aumentar a liquidez das ações da respectiva empresa (Kyle, 1985, Diamond e Verrecchia, 1991, Verrecchia, 2001). Consistente com estas teorias, encontrou-se que as empresas que aderiram aos novos mercados da BOVESPA apresentaram maior liquidez que as empresas transacionadas no mercado tradicional. No entanto, encontrou-se evidência de que apenas as empresas que aderiram ao Nível 2 e ao Novo Mercado experimentaram um aumento de liquidez enquanto que as empresas que aderiram ao Nível 1 experimentaram níveis semelhantes de liquidez antes e após a adesão. Estes resultados contribuem para a literatura de disclosure e de governança ao promoverem evidência de que as empresas que aderiram aos novos mercados são recompensadas com maiores níveis de liquidez nos seus papéis. Além disso, os resultados sugerem que o aumento de liquidez é função do nível do aumento de disclosure e de governança uma vez que empresas que aderiram ao Nível 2 e ao Novo Mercado experimentaram benefícios maiores que as empresas que aderiram ao Nível 1.

De Carvalho e Pennacchi (2007) também estudaram as conseqüências das empresas que aderiram os novos mercados da BOVESPA. O nosso estudo difere do estudo de De Carvalho e Pennacchi em alguns aspectos importantes: 1 - investigamos os determinantes da adesão aos novos mercados, o que permite entender as características das empresas que voluntariamente decidiram aumentar seus níveis de disclosure e de governança de uma companhia. 2 - De Carvalho e Pennacchi utilizaram o volume de negociação da ação como medida de liquidez. Neste artigo 
utilizamos quatro medidas de liquidez (incluindo volume) de modo a mais precisamente mensurar o conceito de liquidez empregado nos modelos teóricos de disclosure. Neste aspecto, o nosso estudo deve ser visto como uma complementação do estudo de De Carvalho e Pennacchi (2007). 3 - exploramos as diferenças na legislação entre os novos mercados e encontramos que maiores níveis de disclosure e governança são associados com maiores aumentos de liquidez.

A próxima seção descreve os novos mercados da BOVESPA. A seção 3 revisa a literatura e descreve a metodologia utilizada. A seção 4 descreve as características da amostra e apresenta os resultados. A seção 5 sintetiza as conclusões do estudo.

\section{Níveis de Governança da BOVESPA}

Implantados em dezembro de 2000 pela BOVESPA, o Novo Mercado e os Níveis Diferenciados de Governança Corporativa - Nível 1 e Nível 2 - são segmentos especiais de listagem que foram desenvolvidos com o objetivo de proporcionar um ambiente de negociação que estimulasse, ao mesmo tempo, o interesse dos investidores e a valorização das companhias. O apêndice 1 apresenta uma comparação entre os diferentes mercados.

Empresas listadas nesses segmentos oferecem aos seus acionistas investidores melhorias nas práticas de governança corporativa que ampliam os direitos societários dos acionistas minoritários e aumentam a transparência das companhias, com divulgação de maior volume e melhor qualidade de informações, facilitando o acompanhamento de seu desempenho. A premissa básica é que a adoção de boas práticas de governança corporativa pelas companhias confere maior credibilidade ao mercado acionário e, como conseqüência, aumenta a confiança e a disposição dos investidores em adquirirem as suas ações e pagarem um preço melhor por elas, reduzindo, como conseqüência, seu custo de captação.

As Companhias Nível 1 se comprometem, principalmente, com melhorias na prestação de informações ao mercado e com a dispersão acionária. Por exemplo, a companhia aberta listada no Nível 1 tem como obrigações adicionais a complementação das Informações Trimestrais (ITRs) e das Informações Anuais (IANs) e a permanência de uma parcela mínima de $25 \%$ das ações em circulação no mercado.

As Companhias Nível 2 se comprometem a cumprir as regras aplicáveis ao Nível 1 e, adicionalmente, um conjunto mais amplo de práticas de governança relativas aos direitos societários dos acionistas minoritários. Por exemplo, a companhia aberta listada no Nível 2 tem como obrigações adicionais a divulgação de demonstrações financeiras de acordo com padrões internacionais IFRS ou US GAAP, a manutenção de um Conselho de Administração com mínimo de 5 (cinco) membros, mandato unificado de até 2 (dois) anos, e no mínimo $20 \%$ de conselheiros independentes.

O Novo Mercado é um mercado voltado principalmente, mas não exclusivamente, a empresas que venham abrir capital na BOVESPA. A principal inovação do Novo Mercado, em relação à legislação, é a exigência de que o capital social 
da companhia seja composto somente por ações ordinárias. Portanto, só é permitido acesso ao Novo Mercado da BOVESPA a empresas que venham a abrir capital ou a empresas previamente listadas que tenham apenas ações ordinárias ou que possam, no caso de existência de ações preferenciais, convertê-las em ações ordinárias. Além disso, a companhia aberta participante do Novo Mercado deve atender a todas as medidas requeridas às empresas Nível 2.

Os novos mercados da BOVESPA têm como objetivo aumentar o nível de governança das empresas e a qualidade das informações disponíveis aos investidores. Os mercados Nível 1 e Nível 2 têm como alvo empresas listadas na BOVESPA enquanto que o Novo Mercado tem como alvo empresas que venham listar capital na BOVESPA. Além disso, o Nível 1 apresenta um maior foco na qualidade das informações disponíveis aos investidores enquanto que o Nível 2 e o Novo Mercado adicionam uma preocupação com maiores níveis de governança corporativa.

\section{Metodologia}

Esta seção descreve a metodologia utilizada no artigo para estudar os determinantes e as conseqüências da adesão aos novos mercados da BOVESPA.

\subsection{Determinantes da adesão}

O primeiro questionamento do artigo estuda os determinantes da adesão aos novos mercados. Uma vez que a adesão aos novos mercados representa uma opção por uma melhoria nos níveis de disclosure e de governança corporativa, utilizouse como referência a literatura nestas duas áreas como base das variáveis incluídas neste estudo.

\section{Revisão da literatura}

Do ponto de vista de disclosure, alguns artigos estudaram os determinantes do nível de disclosure das empresas. Por exemplo, Lang e Lundholm (1993) estudaram os determinantes dos níveis de disclosure de empresas americanas e encontraram que estes são função do tamanho da empresa, do desempenho passado da empresa e da necessidade de investimento. Leuz e Verrecchia (2000) estudaram as características das empresas que aumentaram os níveis de disclosure ao listarem-se no Neuer Markt da Alemanha e confirmaram que a decisão de listar-se neste mercado é função do tamanho da empresa e da necessidade de investimento. Além disso, baseado no estudo de Leuz (1999), Leuz e Verrecchia (2000) encontraram que a decisão de listar-se no Neuer Markt é também função da concentração acionária da empresa e do fato de a empresa ter ações negociadas em outros mercados (por exemplo, ADRs).

Do ponto de vista de governança corporativa, Doidge et alii (2004) desenvolveram um modelo em que a decisão da empresa de aumentar seu nível de governança corporativa (mais especificamente ao listar ADRs) é função do nível de expropriação dos acionistas minoritários por parte dos acionistas majoritários e das necessidades de crescimento das empresas (ver também Benos e Weisbach 
(2004) e Doidge (2003)). Além disso, Silveira et alii (2004) e Silveira et alii (2007) estudaram os determinantes de níveis de governança corporativa das empresas brasileiras e encontraram que o nível de governança corporativa é função do tamanho, do desempenho, da emissão de ADRs e da estrutura de capital da empresa.

Portanto, a decisão de listar-se em um novo mercado deve ser função do porte da empresa, da necessidade de investimento, da concentração acionária, da negociação em outros mercados e da estrutura de capital. A próxima seção descreve a mensuração destas variáveis.

\section{Metodologia e mensuração das variáveis}

Baseado na literatura acima, utilizou-se as seguintes variáveis como potenciais determinantes da adesão aos novos mercados da BOVESPA. LOG(Ativo Total) é o logaritmo do ativo total da empresa ao final do ano $t-1$. $R O A$ é o lucro operacional dividido pelo ativo total médio durante o ano $t-1 . \Delta P L_{t+1}$ é o crescimento percentual no patrimônio líquido da empresa do ano t ao ano $t+1$. Dispersão é o percentual de ações preferenciais no capital social da empresa ao final do ano $t-1$. ADR é uma variável dummy classificada como 1 se a empresa possuía ADRs negociadas na NYSE durante o ano $t-1$ e 0 caso contrário. $\Delta$ Vendas é o crescimento percentual de vendas totais do ano $t-1$ ao ano $t$. Endividamento é o ativo total menos o patrimônio líquido dividido pelo ativo total ao final do ano $t-1$. Além disso, adicionaram-se variáveis dummy para o ano da decisão e para o setor da empresa de forma a controlar para efeitos macroeconômicos e específicos que possam levar a uma maior adesão aos novos mercados em um ano ou setor específico.

Dada a discussão acima, estimou-se o seguinte modelo:

$$
\begin{array}{r}
\text { Novos Mercados }_{t}=\beta_{0}+\beta_{1} \text { LOG }(\text { Ativo Total })_{t-1}+\beta_{2} \text { ROA }_{t-1}+ \\
\beta_{3} \Delta P L_{t, t+1}+\beta_{4} \text { Dispersão }_{t-1}+\beta_{5} \text { ADR }_{t-1}+\beta_{6} \Delta \text { Vendas }_{t-1, t}+ \\
\beta_{7} \text { Endividamento }_{t-1}+\sum \beta_{j} \text { Ano }_{j}+\sum \beta_{i} \text { Setor }_{i}+\epsilon
\end{array}
$$

onde Novos Mercados $t$ é uma variável dummy definida como '1' se a empresa está listada em um dos novos mercados no ano $t$ e ' 0 ' se a empresa está no mercado tradicional da BOVESPA no ano $t$. Dado que a variável dependente é uma variável categórica e dicotômica, utilizou-se um modelo PROBIT com dados em painel. Baseado na literatura acima, os coeficientes de $\beta_{1}$ a $\beta_{6}$ deveriam ser positivos e $\beta_{7}$ deveria ser negativo.

\subsection{Consequiências da adesão}

\section{Revisão da literatura}

O segundo questionamento do artigo estuda as conseqüências da adesão aos novos mercados. Esta parte do artigo baseia-se em diversas teorias que mostram que maiores níveis de disclosure e de governança reduzem a assimetria de 
informação entre acionistas e gestores e, também, reduzem a possibilidade de expropriação de acionistas minoritários, portanto, deveria ser recompensada com uma maior liquidez das ações e um menor custo de capital (Copeland e Galai, 1983, Kyle, 1985, Glosten e Milgrom, 1985, Diamond e Verrecchia, 1991). Estimar o custo de capital tem sido um desafio para a literatura de finanças. Então, para este caso, optou-se por avaliar somente o impacto da decisão de listar nos novos mercados do ponto de vista de liquidez. Brennan e Subrahmanyam (1996) e Bekaert et alii (2007) mostraram que um maior nível de liquidez das ações é associado com um menor custo de capital.

Alguns autores estudaram as conseqüências da adoção a maiores níveis de disclosure e de governança corporativa. Leuz e Verrecchia encontraram que as empresas que aderiram ao Neuer Markt apresentaram um menor bid-ask spread e um maior volume de negociação do que as demais empresas (ver também Verrecchia (2001) para uma survey da literatura de disclosure). No mercado brasileiro, De Carvalho (2003) e De Carvalho e Pennacchi (2007) estudaram as conseqüências das empresas que aderiram aos novos mercados da BOVESPA. Estes autores encontraram que as empresas que aderiram aos novos mercados da BOVESPA durante os anos de 2001 a 2003 obtiveram um aumento no preço das ações (principalmente das ações preferenciais) e um aumento no volume de negociação. Dado que volume de negociação pode ser interpretado como uma medida de liquidez (ver também discussão abaixo), o objetivo desta seção do artigo (isto é, de estudar as conseqüências da adesão) é semelhante ao do estudo de De Carvalho e Pennacchi (2007).

\section{Metodologia e mensuração das variáveis}

Esta seção descreve a metodologia utilizada para testar as conseqüiências da adesão aos novos mercados do ponto de vista da liquidez das ações da empresa. Para tal, é necessário obter medidas de liquidez, uma variável que capture a adesão aos novos mercados, e uma série de variáveis de controle. O objetivo é de estimar o seguinte modelo:

$$
\begin{aligned}
\text { Liquidez } & \beta_{0}+\beta_{1} \text { NovosMercados } \\
& +\sum \beta_{m} \text { Variaveis de } \text { Controle }_{m}+\epsilon
\end{aligned}
$$

onde Liquidez é uma das medidas de liquidez descrita abaixo, NovosMercados é uma variável dummy definida como ' 1 ' se a empresa listou-se em um dos novos mercados no ano $t$ e ' 0 ' se a empresa listou-se no mercado tradicional da BOVESPA no ano $t$, e Variáveis de Controle é um vetor de variáveis de controle demonstrado pela literatura a influenciar a liquidez das ações de uma empresa. $\mathrm{O}$ coeficiente $\beta_{1}$ mede a diferença de liquidez entre as empresas que aderiram aos novos mercados após a adesão e a liquidez das demais empresas que não aderiram aos novos mercados. Dado que as variáveis dependentes (descritas abaixo) são 
inversamente proporcionais à liquidez, um aumento de liquidez após a adesão aos novos mercados seria compatível com um coeficiente $\beta_{1}$ negativo.

Dado que a variável dependente é uma variável contínua, estimou-se o modelo acima através do método de mínimos quadrados ordinários (MQO) com dados em painel. Devido a potencial dependência das observações, controlou-se para efeitos fixos anuais e do setor da empresa. Dessa forma pode-se controlar para a mudança de liquidez no mercado acionário como um todo e para as variações de liquidez entre setores. Por exemplo, durante 2001, quando um grande bloco de empresas migrou para o Nível 1, houve uma queda acentuada no volume negociado na BOVESPA. Além disso, a significância estatística dos coeficientes da regressão foi ajustada (clustered) para cada empresa. Este método é recomendado por Petersen (2008) em aplicações em finanças corporativas. ${ }^{1}$

\section{Medidas de liquidez e variáveis de controle}

A definição de liquidez tradicionalmente utilizada na literatura é a habilidade de transacionar um alto volume de ações sem mover o preço da ação (Pastor e Stambaugh, 2003). Existem varias medidas de liquidez utilizadas na literatura que tentam capturar o conceito de liquidez descrito acima. Neste estudo optou-se por utilizar quatro medidas de liquidez dado que cada medida apresenta vantagens e desvantagens. Para calcular as medidas de liquidez, utilizou-se o seguinte critério. Primeiramente foi selecionado o papel de maior liquidez de cada empresa (ações preferenciais ou ordinárias). Especificamente, se a empresa transacionava ações ordinárias e preferenciais, utilizou-se para o cálculo de liquidez as ações preferenciais. Para as demais empresas utilizou-se as ações ordinárias. Desta forma, é possível comparar a liquidez de papéis de empresas antes e depois da adesão aos novos mercados, até mesmo para empresas que converteram ações preferenciais em ordinárias para aderir ao Novo Mercado. Além disso, somente foi computada as variáveis de liquidez para empresas com pelo menos 50 dados diários durante o ano (entendendo-se o total de dias negociados durante um ano civil), excluído-se assim empresas sem dados disponíveis em pelo menos $20 \%$ do ano.

A primeira medida de liquidez é o conceito de retorno zero sugerido por Lesmond et alii (1999) e adaptado por Bekaert et alii (2007). A lógica desta medida é que se o valor da informação revelada ao mercado for inferior ao custo de transação da ação, então os investidores escolherão não transacionar a ação, o que manterá o preço do papel inalterado. Desta maneira empresas com maior incidência de dias em que o retorno da ação é igual a zero tendem a serem empresas com maior custo de transação e, portanto menor liquidez. Esta medida é freqüentemente utilizada em estudos internacionais devido à escassez de dados sobre o volume da empresa

\footnotetext{
${ }^{1}$ Conforme descrito a seguir, duas das variáveis de liquidez apresentam valores entre zero e um, o que sugeriria a estimação de um modelo de TOBIT. Como análise de sensibilidade, todas as regressões utilizando estas variáveis foram re-estimadas utlizando o modelo de TOBIT e os resultados apresentam as mesmas inferências que quando utlizado o método de MQO. No entanto, dado a dificuldade de ajustar (cluster) o erro padrão no modelo de TOBIT, optou-se por apresentar os resultados mais conservadores seguindo a metodologia de Petersen (2008).
} 
(e.g., Ashbaugh-Skaife et alii (2006), Bekaert et alii (2007) e Daske et alii (2007)) e é utilizada neste artigo de forma a permitir a comparação com estes estudos.

Para calcular a medida de Zero Retorno, identificaram-se cada um dos dias em que o retorno diário da ação foi igual a zero (vale notar que isto não significa que a empresa não foi negociada - atendeu-se a esta limitação ao utilizar as medidas abaixo) e calculou-se o percentual destes dias em relação ao número de dias em que houve negociação no período. Por exemplo, para uma empresa com 250 dias com retornos diários disponíveis e 50 dias com retornos diários iguais a zero, o valor da variável Zero Retorno é igual a 0.20 (ou 20\%).

A segunda medida de liquidez utilizada neste artigo é semelhante à variável Zero Retorno mas tira proveito do fato que volume transacionado é disponível para as empresas brasileiras através do banco de dados Economática. Dessa forma calculou-se a variável Zero Volume de maneira semelhante à mensuração da variável Zero Retorno. Especificamente, identificaram-se cada um dos dias em que o volume negociado foi igual a zero e calculou-se o percentual destes dias em relação ao número de dias em que houve negociação no período. Por exemplo, para uma empresa com 250 dias úteis disponíveis e 50 dias com volume negociado igual a zero, o valor da variável Zero Volume é igual a 0.20 (ou 20\%).

A terceira medida de liquidez utilizada neste artigo é a medida desenvolvida por Amihud (2002). Esta variável é motivada pela medida de price impact proposta por Kyle (1985) e academicamente reconhecida como Kyle Lambda. Intuitivamente a medida de Amihud mede o movimento diário no preço da ação associado a uma unidade de negociação (no caso de Amihud a unidade utilizada é o dólar americano - US\$ - e no caso deste artigo utilizou-se Real - R\$). A idéia é que em ações de alta liquidez seja possível negociar altos valores sem que haja alteração no valor da ação (neste caso, o valor da variável Amihud será pequeno e igual a zero).

Para estimar a medida de Amihud, também se selecionou o papel de maior liquidez de cada empresa. Em seguida, calculou-se a fração do retorno absoluto diário da ação com o volume negociado. Isto é, para cada dia em que a empresa foi negociada (isto é, o volume negociado foi positivo) calculou-se a seguinte fórmula:

$$
\text { Impacto }_{i, t}=\left(\mid \text { Retorno }_{i, t} \mid x 10^{6}\right) /\left(\text { Volume }_{i, t}\right)
$$

onde Retorno é o retorno diário da ação $i$ no dia $t$ e Volume é o volume negociado em Reais (R\$) da ação $i$ no dia $t$. Em seguida, conforme Daske et alii (2007), calculou-se a mediana da medida Impacto durante o ano e obteve-se o logaritmo dessa medida para diminuir o efeito de outliers.

De Carvalho e Pennacchi (2007) utilizaram o volume de negociação da ação como medida de liquidez. A idéia desta variável é que o volume de negociação é maior quando investidores estão mais dispostos a negociar a ação, que por sua vez é maior quando a liquidez da ação é maior. Apesar de volume ser uma medida intuitiva de liquidez alguns artigos mostram que volume pode também ser uma medida inadequada de liquidez. Por exemplo, Jones (2002) não encontrou 
evidência da relação entre mudanças no volume de negociação e mudanças no bid-ask spread de empresas americanas. Da mesma forma, Foster e Viswanathan (1993) e Lee et alii (1993) encontraram uma correlação negativa entre o volume de negociação e a liquidez das ações. De qualquer forma, para efeitos de comparação com o estudo de De Carvalho e Pennacchi (2007), a quarta medida de liquidez utilizada neste artigo é o volume de negociação da ação durante o ano (Volume). Para facilitar a comparação com as demais variáveis que são decrescentes em liquidez, multiplicou-se Volume por menos um de forma que esta variável também é decrescente em liquidez.

Além disso, conforme Daske et alii (2007), utilizou-se como variáveis de controle o tamanho da empresa, a volatilidade das ações, a presença no Ibovespa, e a existência de ADR. LOG (Ativo Total) é o logaritmo do ativo total da empresa. Volatilidade é o desvio padrão dos retornos diários da ação durante o ano. Ibovespa é uma variável dummy classificada como 1 se a empresa fazia parte do índice Ibovespa durante o ano e 0 caso contrário. ADR é uma variável dummy classificada como 1 se a empresa possuía ADRs negociadas na NYSE durante o ano e 0 caso contrário.

\section{Especificação alternativa}

Um problema na estimação da equação 2 é que se supõe que as variáveis explanatórias são exógenas. Isto é, estas variáveis não são correlacionadas com o termo de erro da equação 2. No entanto, é possível que a decisão de elevar os níveis de disclosure e de governança corporativa sejam função dos níveis de liquidez das ações destas empresas (ver também discussão em Leuz e Verrecchia (2000) e Silveira et alii (2007)). Larcker e Rusticus (2007) estudam as implicações dos problemas de endogeneidade em estudos empíricos e demonstram a dificuldade de resolver este problema. Além disso, outra limitação do modelo na Equação 2 é que o modelo pressupõe o controle de todas as variáveis que afetam liquidez. Para tanto adicionou-se uma série de variáveis que afetam liquidez como variáveis de controle. No entanto, é possível que algum determinante de liquidez não tenha sido incluído no modelo. Dessa forma, se a variável omitida for correlacionada com a variável Novos Mercados, a estimação do coeficiente $\beta_{1}$ será viesada.

Em vez de tentar resolver a questão de endogeneidade e da potencial omissão de uma variável correlacionada, optou-se por a metodologia utilizada em Daske et alii (2007). A idéia é incluir uma variável dummy que identifique as empresas da amostra de tratamento (neste caso empresas que aderiram aos novos mercados) durante o período anterior ao da adesão. Isto é, a adição desta variável exerce o papel de um efeito fixo que controla para o nível de liquidez antes da adesão, permitindo que a variável Novos Mercados na equação 2 capture o aumento na liquidez (em vez de o nível de liquidez) após a adesão. Além disso, essa variável permite atenuar (mas provavelmente não resolver) a preocupação com endogeneidade uma vez que é possível controlar para o efeito de qualquer variável constante ao longo do tempo, mesmo que omitida do modelo. Dessa forma estimou-se o se- 
guinte modelo (utilizando a mesma metodologia utilizada na estimação da equação 2):

$$
\begin{aligned}
\text { Liquidez } & =\gamma_{0}+\gamma_{1} \text { Novos Mercados }+\gamma_{2} \text { Empresas Novos } \\
\text { Mercados } & +\sum \gamma_{m} \text { Variaveis de Controle } \text { Cl }_{m}+\epsilon
\end{aligned}
$$

Desta forma, o coeficiente $\gamma_{1}$ na equação 4 mede o aumento de liquidez nos papéis da empresa após a adesão. O coeficiente $\gamma_{2}$ mede a diferença de liquidez entre os papéis das empresas que aderiram aos novos mercados no período anterior à adesão e a liquidez dos papéis das demais empresas transacionadas na BOVESPA. Dado que as variáveis Zero Retorno e Amihud são inversamente proporcionais à liquidez, um aumento de liquidez após a adesão dos novos mercados seria compatível com um coeficiente $\gamma_{1}$ negativo.

\section{Descrição da Amostra e Análise dos Resultados}

\subsection{Descrição da Amostra}

Para a definição da amostra selecionou-se todas as empresas listadas na BOVESPA com cotações na versão de 2007 do banco de dados Economática. ${ }^{2}$ Além disso, levantaram-se todas as empresas que aderiram ao Novo Mercado, Nível 1 e Nível 2 de governança corporativa da BOVESPA entre os anos de 2001 a 2005. Esta informação foi obtida diretamente do website da BOVESPA e a lista destas empresas encontra-se no Apêndice 1. Finalmente, coletaram-se da Economática as cotações de fechamento diárias de cada ação ajustada para o pagamento de dividendos, o volume de transação diário e os respectivos dados contábeis . A amostra final contém 1579 observações durante o período de 2001 a 2005.

A Tabela 1 apresenta o número de empresas transacionadas e quantas pertenciam aos diferentes níveis de governança corporativa da BOVESPA durante o período de 2001 até 2005. Em 2001, 13 empresas aderiram ao Nível 1 e este número cresceu a 34 empresas ao final de 2005. Da mesma forma, 3 (2) empresas aderiram ao Nível 2 (Novo Mercado) da BOVESPA em 2002 e este número cresceu a 10 (16) empresas ao final de 2005. Além disso, a Tabela 1 apresenta o número de ações da nossa amostra que transacionaram suas ações no mercado principal da BOVESPA. Devido à migração aos novos mercados da BOVESPA, o número de empresas no mercado principal caiu de 293 empresas em 2001 para 267 empresas em 2005.

${ }^{2}$ Como tomamos os dados de 2007 é possível que tenhamos um viés de sobrevivência pois empresas que não façam parte deste banco de dados não são consideradas no estudo. 
Tabela 1

Total de empresas em cada mercado por ano

A tabela 1 apresenta o número de eventos por ano que foram constatados para a realização desse estudo. BOVESPA - Empresas que transacionadas na BOVESPA durante o ano e com informações no Economática. Nível 1 - Empresas que aderiram à modalidade Nível 1 de Governança Corporativa da BOVESPA no ano. Nível 2 - Empresas que aderiram à modalidade Nível 2 de Governança Corporativa da BOVESPA no ano. Novo Mercado - Empresas que aderiram à modalidade Novo Mercado de Governança Corporativa da BOVESPA no ano.

\begin{tabular}{l|c|c|c|c}
\hline & \multicolumn{5}{|c}{ Total de empresas em cada mercado da BOVESPA por ano } \\
\hline Ano & BOVESPA & Nível 1 & Nível 2 & Novo Mercado \\
\hline 2001 & 293 & 13 & 0 & 0 \\
\hline 2002 & 287 & 19 & 3 & 2 \\
\hline 2003 & 284 & 27 & 3 & 2 \\
\hline 2004 & 275 & 30 & 7 & 7 \\
\hline 2005 & 267 & 34 & 10 & 16 \\
\hline Total & & 34 & 10 & 16 \\
\hline
\end{tabular}

\subsection{Determinantes da adesão aos novos mercados}

Esta seção estuda os determinantes da adesão aos novos mercados da BOVESPA. O objetivo é estudar quais as características das empresas que aderiram aos novos mercados e comparar se suas características são semelhantes às evidencias encontradas na literatura.

A Tabela 2 - Painel A apresenta as estatísticas descritivas da amostra. A média da variável Novos Mercados é 0,11 , o que significa que $11 \%$ das observações são empresas transacionadas em algum dos novos mercados da BOVESPA. A tabela também apresenta informações sobre as variáveis de controle do modelo que estuda os determinantes da adesão aos novos mercados. Observou-se que a lucratividade média é de $-3 \%$, que na média as empresas incluídas na nossa amostra têm $28 \%$ de suas ações em posse de acionistas minoritários e que o endividamento médio é de $69 \%$. Alem disso, $15 \%$ das observações contém empresas com ADR negociadas na bolsa de Nova Iorque.

O Painel B apresenta a matriz de correlações entre as variáveis incluídas no Painel A. Neste caso, conforme os outros artigos nesta área, observou-se que a variável Novos Mercados é positivamente correlacionada com as demais variáveis com a exceção de endividamento em que a correlação é negativa. Isto significa que a decisão de listar-se nos novos mercados é positivamente relacionada com o tamanho da empresa, lucratividade, dispersão acionária, presença de ADR, crescimento das vendas, crescimento do patrimônio líquido e negativamente relacionada com o endividamento. No entanto, como essa análise não leva em consideração o efeito simultâneo das demais variáveis, deve-se ser interpretada com cautela. 
Tabela 2

Características da amostra

Painel A apresenta as estatísticas descritivas das variáveis listadas abaixo. Painel B apresenta a matriz de correlação entre as variáveis analisadas no estudo. Novos Mercados - Variável dummy classificada como 1 se a empresa fazia parte de um dos novos mercados da BOVESPA (Novo Mercado, Nível 1, e Nível 2) durante o ano e 0 caso contrário. LOG (Ativo Total) - Logaritmo do ativo total das empresas listadas na BOVESPA. ROA - Lucro operacional dividido pelo ativo total médio durante o ano. Dispersão - Percentual de ações em posse de acionistas minoritários. $A D R$ - Variável dummy classificada como 1 se a empresa possuía ADRs negociadas na NYSE durante o ano e 0 caso contrário. Endividamento - Ativo total menos o patrimônio líquido dividido pelo ativo total. $\Delta$ Vendas - Alteração nas vendas durante o ano dividido pelo ativo total no ano anterior. $\Delta P L_{t+1}$ - Alteração no patrimônio líquido durante o ano dividido pelo ativo total no ano anterior.

Painel A - Estatísticas descritivas

\begin{tabular}{l|c|c|c|c|c}
\hline & OBS & Média & STD & Mín & Máx \\
\hline NM & 1579 & 0.11 & 0.31 & 0.00 & 1.00 \\
\hline LOG (AT) & 1579 & 13.29 & 2.22 & 5.80 & 18.86 \\
\hline ROA & 1579 & -0.03 & 0.28 & -1.93 & 0.33 \\
\hline Dispersão & 1579 & 27.96 & 24.74 & 0.00 & 84.20 \\
\hline ADR & 1579 & 0.15 & 0.36 & 0.00 & 1.00 \\
\hline Endivid. & 1579 & 0,69 & 2.69 & 0.01 & 1.00 \\
\hline$\Delta$ Vendas & 1579 & 0.08 & 0.20 & -0.95 & 1.10 \\
\hline$\Delta P L_{t+1}$ & 1250 & -0.02 & 0.27 & -1.78 & 1.11 \\
\hline
\end{tabular}

\begin{tabular}{l|c|c|c|c|c|c|c|c}
\hline \multicolumn{2}{l|}{ Painel B - Matriz de Correlações } & $\begin{array}{c}\text { AOG } \\
\text { (AT) }\end{array}$ & RMA & Dispersão & ADR & Endivid. & $\begin{array}{c}\Delta \\
\text { Vendas }\end{array}$ & $\begin{array}{c}\Delta \\
\text { PL }_{t+1}\end{array}$ \\
\hline NM & 1 & 0,35 & 0,14 & 0,22 & 0,37 & $-0,06$ & 0,03 & 0,08 \\
\hline LOG (AT) & & 1 & 0,41 & 0,07 & 0,46 & $-0,28$ & 0,01 & 0,27 \\
\hline ROA & & & 1 & 0,06 & 0,11 & $-0,73$ & 0,19 & 0,59 \\
\hline Dispersão & & & & 1 & 0,23 & $-0,04$ & 0,05 & $-0,01$ \\
\hline ADR & & & & & 1 & $-0,07$ & 0,01 & 0,08 \\
\hline Endivid. & & & & & & 1 & $-0,09$ & $-0,47$ \\
\hline$\Delta$ Vendas & & & & & & 1 & 0,21 \\
\hline$\Delta$ PL $_{t+1}$ & & & & & & & & 1 \\
\hline
\end{tabular}

A Tabela 3 estuda os determinantes da adesão aos novos mercados da BOVESPA. A variável dependente é Novos Mercados e estimou-se o modelo de PROBIT. As primeiras duas colunas apresentam o modelo sem a variável de crescimento do patrimônio líquido. Isto se deve ao fato de que a amostra disponível para esta variável ser menor. No primeiro modelo, encontrou-se que o tamanho, lucratividade, dispersão acionária e a presença de ADR aumentam a probabilidade de adesão aos novos mercados. No entanto, não se encontrou evidência do efeito do endividamento ou do crescimento das vendas na propensão da empresa listar-se nos novos mercados. A coluna II apresenta o modelo anterior com a adição das variáveis dummies para o setor da empresa. Neste caso, o efeito do endividamento ou do crescimento das vendas torna-se significativo ao nível de $10 \%$. As colunas 
III e IV apresentam os resultados após a inclusão da variável de crescimento do patrimônio líquido. Neste caso, não se encontrou evidência de que a propensão de adesão aos novos mercados é relacionada ao crescimento do patrimônio líquido. Além disso, devido à redução no tamanho da amostra, os efeitos das variáveis de endividamento e crescimento das vendas tornaram-se não significativos.

Tabela 3

Determinantes da adesão aos novos mercados

Esta tabela apresenta os determinantes da adesão a novos mercados da BOVESPA (Novo Mercado, Nível 1, e Nível 2). A variável dependente é Novos Mercados e o modelo estimado é o modelo de PROBIT. Novos Mercados Variável dummy classificada como 1 se a empresa fazia parte de um dos novos mercados da BOVESPA (Novo Mercado, Nível 1, e Nível 2) durante o ano e 0 caso contrário. LOG (Ativo Total) - Logaritmo do ativo total das empresas listadas na BOVESPA. ROA - Lucro operacional dividido pelo ativo total médio durante o ano. Dispersão - Percentual de ações em posse de acionistas minoritários. ADR - Variável dummy classificada como 1 se a empresa possuía ADRs negociadas na NYSE durante o ano e 0 caso contrário. Endividamento - Ativo total menos o patrimônio líquido dividido pelo ativo total. $\Delta$ Vendas - Alteração nas vendas durante o ano dividido pelo ativo total no ano anterior. $\Delta P L_{t+1}$ - Alteração no patrimônio líquido durante o ano dividido pelo ativo total no ano anterior. Estatísticas $t$ são apresentadas em itálicos abaixo dos coeficientes estimados pelo modelo.

\begin{tabular}{l|c|c|c|c|c}
\hline \multirow{2}{*}{ Intercepto } & Sinal & I & II & III & IV \\
\cline { 2 - 6 } & & $-5,75$ & $-7,99$ & $-6,09$ & $-8,29$ \\
\hline \multirow{2}{*}{ LOG (AT) } & + & $-11,96$ & $-0,43$ & $-10,48$ & $-0,45$ \\
\cline { 2 - 6 } & & 0,27 & 0,43 & 0,29 & 0,43 \\
\cline { 2 - 6 } & + & 1,35 & 0,48 & 1,08 & 0,14 \\
\hline \multirow{2}{*}{ Dispersão } & + & 2,05 & 0,64 & 1,49 & 0,16 \\
\cline { 2 - 6 } & & 5,83 & 5,77 & 4,87 & 0,01 \\
\hline \multirow{2}{*}{ ADR } & + & 0,52 & 0,58 & 0,54 & 0,29 \\
\cline { 2 - 6 } & & 4,03 & 3,66 & 3,55 & 3,17 \\
\cline { 2 - 6 } & - & $-0,1$ & $-0,48$ & 0,06 & $-0,32$ \\
\hline \multirow{2}{*}{$\Delta$ Vendivid. } & + & $-0,49$ & $-1,78$ & 0,36 & -1 \\
\cline { 2 - 6 } & & 0,42 & 0,74 & $-0,22$ & 0,18 \\
\hline \multirow{2}{*}{$\Delta P L_{t+1}$} & + & & & $-0,55$ & 0,31 \\
\cline { 2 - 6 } & & & & 0,34 & 0,19 \\
\hline Ano dummies & & Sim & Sim & Sim & Sim \\
\hline Setor dummies & & Não & Sim & Não & Sim \\
\hline Adj-R ${ }^{2}(\%)$ & & 19,99 & 26,61 & 17,85 & 23,84 \\
\hline OBS & & 1579 & 1579 & 1250 & 1250 \\
\hline
\end{tabular}

Em geral, os resultados da Tabela 3 são consistentes com resultados da literatura que estuda a adesão de altos níveis de governança corporativa e de disclosure. Isto é, encontrou-se evidência de que a adesão aos novos mercados da BOVESPA é influenciada pelo tamanho, lucratividade, dispersão acionária e a presença de ADR na empresa. No entanto, o efeito do endividamento e do crescimento das vendas em poucas vezes apresentou significância estatística. Além disso, não encontrouse evidência da influência do crescimento do patrimônio líquido (a nossa proxy 
da necessidade de financiamento externo) na probabilidade de adesão dos novos mercados.

\subsection{Conseqüências da adesão aos novos mercados}

Esta seção estuda as conseqüências da adesão aos novos mercados da BOVESPA. Conforme apresentado na seção 2, diversas teorias sugerem que a adesão a melhores níveis de governança corporativa e de disclosure representa um comprometimento da empresa com maior transparência contábil e sugere um menor risco de expropriação dos acionistas minoritários e, portanto, deveria ser recompensada com uma maior liquidez dos papéis da empresa. Portanto, estudou-se a possibilidade das empresas que aderiram aos novos mercados da BOVESPA serem recompensadas com uma maior liquidez de seus papéis conforme as medidas de Zero Retorno e a variável de liquidez proposta por Amihud (2002).

A Tabela 4 - Painel A apresenta as estatísticas descritivas das variáveis utilizadas nesta parte do artigo. A média da variável Zero Retorno é 0,55, o que significa que na média as empresas incluídas na nossa amostra apresentam 55\% dos dias com retornos iguais a zero (a nossa proxy para a negociação da ação) na BOVESPA. Da mesma forma, média da variável Zero Volume é 0,56, o que significa que na média as empresas incluídas na nossa amostra apresentam $56 \%$ dos dias sem negociação. Mais importante, ambas as variáveis apresentam bastante variabilidade uma vez que o valor mínimo dessas variáveis é zero (a empresa foi negociada todos os dias) e o valor máximo é um (a empresa não foi negociada durante o ano). A tabela também apresenta estatísticas descritivas para a variável de Amihud e do volume negociado (vale ressaltar que multiplicou-se Volume por menos um de forma que a variável - assim como as demais variáveis - é decrescente em liquidez). Além disso, a tabela apresenta informações da volatilidade das ações e da presença no índice Ibovespa. Em 15\% dos casos a empresa integrou o índice Ibovespa durante o ano.

O Painel B apresenta a matriz de correlações entre as variáveis incluídas no painel A. As quatro variáveis de liquidez são altamente correlacionadas. Por exemplo, a variável de Zero Retorno apresenta uma correlação de 0,77 com Zero Volume, 0,63 como Volume, e 0,68 com Amihud. Além disso, todas as variáveis de liquidez são negativamente correlacionadas com a variável Novos Mercados, sugerindo que empresas transacionadas nos novos mercados da BOVESPA apresentam maior liquidez que as demais empresas. No entanto, como a análise de correlação não permite controlar para outros determinantes de liquidez (como fazem as regressões múltiplas apresentadas a seguir), este resultado deve ser interpretado com cautela. 
Tabela 4

Estatísticas descritivas - conseqüências da adesão

Painel A apresenta as estatísticas das variáveis listadas. Zero Retornot+1 - Percentual de retornos diários igual a zero durante o ano. Zero Volumet+1 - Percentual de dias sem negociação durante o ano. Amihud $d_{t+1}-\mathrm{O}$ logaritmo da mediana do price impact diário onde price impact diário é o valor absoluto do retorno diário dividido pelo volume diário. Volume $_{t+1}$ - Volume em Reais (R\$) negociado durante o ano e multiplicado por menos um. Novos Mercados - Variável dummy classificada como 1 se a empresa fazia parte de um dos novos mercados da BOVESPA (Novo Mercado, Nível 1, e Nível 2) durante o ano e 0 caso contrário. LOG (Ativo Total) Logaritmo do ativo total das empresas listadas na BOVESPA. Volatilidade - Desvio padrão dos retornos diários da ação durante o ano. Ibovespa - Variável dummy classificada como 1 se a empresa fazia parte do índice Ibovespa durante o ano e 0 caso contrário. $A D R$ - Variável dummy classificada como 1 se a empresa possuía ADRs negociadas na NYSE durante o ano e 0 caso contrário.

Painel A - Estatísticas descritivas

\begin{tabular}{l|c|c|c|c|c}
\hline & OBS & Média & STD & Mín & Máx \\
\hline Zero Retorno $_{t+1}$ & 1380 & 0,55 & 0,39 & 0 & 1 \\
Zero Volume $_{t+1}$ & 1380 & 0.56 & 0.38 & 0.04 & 1.00 \\
Amihud $_{t+1}$ & 786 & $-0,59$ & 4,08 & $-8,98$ & 8,08 \\
Volume $_{t+1}$ & 1340 & -14.59 & -6.30 & -28.11 & 1.55 \\
NM & 1380 & 0,12 & 0,33 & 0 & 1 \\
LOG (AT) & 1380 & 13,45 & 2,12 & 5,8 & 18,86 \\
Volatilidade & 1380 & 0,05 & 0,06 & 0 & 0,45 \\
Ibovespa & 1380 & 0,15 & 0,36 & 0 & 1 \\
ADR & 1380 & 0,05 & 0,23 & 0 & 1 \\
\hline
\end{tabular}

\begin{tabular}{l|c|c|c|c|c|c|c|c|c}
\hline Painel B - Matriz de Correlações & $\begin{array}{c}\text { Z } \\
\text { Retorno } t+1\end{array}$ & $\begin{array}{c}\mathrm{Z} \\
\text { Volume }_{t+1}\end{array}$ & Amihud $_{t+1}$ & Vol. $_{t+1}$ & $\mathrm{NM}$ & $\begin{array}{c}\text { Log } \\
(\mathrm{AT})\end{array}$ & Volat. $^{\text {Ibovespa }}$ & ADR \\
\hline $\begin{array}{l}\text { Zero } \\
\text { Retorno }_{t+1}\end{array}$ & 1.00 & 0.77 & 0.68 & 0.63 & -0.34 & -0.58 & -0.24 & -0.50 & -0.26 \\
\hline $\begin{array}{l}\text { Zero } \\
\text { Volume }_{t+1}\end{array}$ & & 1.00 & 0.72 & 0.69 & -0.38 & -0.53 & 0.12 & -0.48 & -0.26 \\
\hline Amihud $_{t+1}$ & & & 1.00 & 0.80 & -0.49 & -0.72 & 0.38 & -0.62 & -0.38 \\
\hline Vol. $_{t+1}$ & & & & 1.00 & -0.41 & -0.59 & 0.18 & -0.47 & -0.32 \\
\hline NM & & & & & 1.00 & 0.36 & -0.09 & 0.30 & 0.47 \\
\hline LOG (AT) & & & & & & 1.00 & -0.07 & 0.53 & 0.32 \\
\hline Volat. & & & & & & & 1.00 & -0.01 & -0.04 \\
\hline Ibovespa & & & & & & & & 1.00 & 0.34 \\
\hline ADR & & & & & & & & & 1.00 \\
\hline
\end{tabular}


A Tabela 5 estuda as conseqüências da adesão aos novos mercados da BOVESPA em relação à variável de Zero Retorno. A variável dependente é Zero Retorno e estimou-se um modelo de regressão linear com o método de mínimos quadrados ordinários. A primeira coluna apresenta os resultados da equação 2 após a inclusão de variáveis dummy para ano. No que diz respeito às variáveis de controle, encontrou-se que as empresas de maior porte, com maior volatilidade das ações e integrantes do índice Ibovespa apresentam uma maior liquidez e um percentual menor de Zero Retorno. Não se encontrou evidência de influência da presença de ADR.

No que diz respeito à variável Novos Mercados, o coeficiente estimado na coluna I é negativo e significativo. Isto significa que as empresas negociadas nos novos mercados da BOVESPA apresentam 16\% menos dias sem retornos em suas ações e, portanto, apresentam maior liquidez. Após a inclusão de variáveis dummy para setor (coluna II), o coeficiente da variável Novos Mercados aumentou (em magnitude) para -0,18 e manteve o nível de significância estatística. Finalmente, após a inclusão da variável Empresas Novos Mercados, observou-se que o coeficiente da variável Novos Mercados reduziu-se para -0,05 e sem significância estatística. Isto significa que, apesar das empresas listadas nos novos mercados apresentarem maior liquidez (como observou-se através do coeficiente de -0,16 da variável Empresas Novos Mercados), estas empresas apresentaram um aumento na liquidez marginal sem significância estatística.

A Tabela 6 estuda as conseqüências da adesão aos novos mercados da BOVESPA em relação à variável de Zero Volume. Os resultados são semelhantes aos resultados utilizando a variável Zero Retorno. Por exemplo, no que diz respeito à variável Novos Mercados, o coeficiente estimado nas colunas I e II são negativos e significativos. Isto significa que as empresas negociadas nos novos mercados da BOVESPA apresentam 19\% menos dias sem negociação em suas ações que as demais empresas transacionadas na BOVESPA. No entanto, após a inclusão da variável Empresas Novos Mercados, observou-se que o coeficiente da variável Novos Mercados reduziu-se para -0,05 e sem significância estatística. Isto significa que, apesar das empresas listadas nos novos mercados apresentarem maior liquidez, essas empresas apresentaram uma redução marginal nos dias sem negociação e sem significância estatística. 
Tabela 5

Consequiências da adesão aos novos mercado - zero retorno

Esta tabela apresenta as conseqüências da adesão aos Novos Mercados da BOVESPA. A variável dependente

é Zero Retorno. O modelo estimado é o modelo de mínimos quadrados ordinários (MQO). Zero Retorno $t+1$

- Percentual de retornos diários igual a zero durante o ano. Novos Mercados - Variável dummy classificada como 1 se a empresa fazia parte de um dos novos mercados da BOVESPA (Novo Mercado, Nível 1, e Nível 2) durante o ano e 0 caso contrário. Empresas Novos Mercados - Variável dummy classificada como 1 para empresas que aderiram aos Novos Mercados durante o ano e 0 caso contrário. LOG (Ativo Total) - Logaritmo do ativo total das empresas listadas na BOVESPA. Volatilidade - Desvio padrão dos retornos diários da ação durante o ano. Ibovespa - Variável dummy classificada como 1 se a empresa fazia parte do índice Ibovespa durante o ano e 0 caso contrário. $A D R$ - Variável dummy classificada como 1 se a empresa possuía ADRs negociadas na NYSE durante o ano e 0 caso contrário.

\begin{tabular}{l|c|c|c}
\hline & \multicolumn{3}{|c}{ Zero Retorno $t+1$} \\
\hline & I & II & III \\
\hline Intercepto & 1,66 & 1,7 & 1,66 \\
\hline & 14,89 & 13,72 & 13,62 \\
\hline Novos Mercados & & & \\
\hline & $-0,16$ & $-0,18$ & $-0,05$ \\
\hline & $-3,10$ & $-3,77$ & $-0,89$ \\
\hline Empresas Novos Mercados & & & \\
\hline & & & $-0,16$ \\
\hline & & & $-2,96$ \\
\hline LOG (Ativo Total) & & & \\
\hline & $-0,08$ & $-0,08$ & $-0,08$ \\
\hline Volatilidade & $-8,57$ & $-9,26$ & $-8,77$ \\
\hline & & & \\
\hline & $-1,88$ & $-1,84$ & $-1,85$ \\
\hline Ibovespa & $-7,65$ & $-7,12$ & $-7,14$ \\
\hline & & & \\
\hline & $-0,26$ & $-0,23$ & $-0,24$ \\
\hline ADR & $-6,00$ & $-4,80$ & $-4,89$ \\
\hline & & & \\
\hline Ano dummies & 0,01 & 0,04 & 0,08 \\
\hline Setor dummies & 0,10 & 0,72 & 1,32 \\
\hline Adj-R ${ }^{2}$ & Sim & Sim & Sim \\
\hline OBS & Não & Sim & Sim \\
\hline & 48,59 & 53,88 & 54,62 \\
\hline & 1380 & 1380 & 1380 \\
\hline & & &
\end{tabular}


Tabela 6

Conseqüências da adesão aos novos mercado - zero volume

Esta tabela apresenta as conseqüências da adesão aos Novos Mercados da BOVESPA. A variável dependente Zero Volume. O modelo estimado é o modelo de mínimos quadrados ordinários (MQO). Zero Volume Vet $_{t}$ - Percentual de dias sem negociação durante o ano. Novos Mercados - Variável dummy classificada como 1 se a empresa fazia parte de um dos novos mercados da BOVESPA (Novo Mercado, Nível 1, e Nível 2) durante o ano e 0 caso contrário. Empresas Novos Mercados - Variável dummy classificada como 1 para empresas que aderiram aos Novos Mercados durante o ano e 0 caso contrário. LOG (Ativo Total) - Logaritmo do ativo total das empresas listadas na BOVESPA. Volatilidade - Desvio padrão dos retornos diários da ação durante o ano. Ibovespa Variável dummy classificada como 1 se a empresa fazia parte do índice Ibovespa durante o ano e 0 caso contrário. $A D R$ - Variável dummy classificada como 1 se a empresa possuía ADRs negociadas na NYSE durante o ano e 0 caso contrário.

\begin{tabular}{l|c|c|c}
\hline & \multicolumn{3}{|c}{ Zero Volume } \\
\hline & I & II & III \\
\hline Intercepto & 1.31 & 1.35 & 1.30 \\
\hline & 10.96 & 9.48 & 9.33 \\
\hline Novos Mercados & & & \\
\hline & -0.19 & -0.19 & -0.05 \\
\hline & -3.39 & -3.79 & -0.79 \\
\hline Empresas Novos Mercados & & & \\
\hline & & & -0.18 \\
\hline & & & -2.86 \\
\hline LOG (Ativo Total) & & & \\
\hline & -0.06 & -0.07 & -0.07 \\
\hline & -6.14 & -7.03 & -6.53 \\
\hline Volatilidade & & & \\
\hline & 0.52 & 0.44 & 0.43 \\
\hline & 2.44 & 2.00 & 1.95 \\
\hline Ibovespa & & & \\
\hline & -0.28 & -0.24 & -0.25 \\
\hline & -5.95 & -4.69 & -4.79 \\
\hline ADR & & & \\
\hline & 0.02 & 0.04 & 0.08 \\
\hline Ano dummies & 0.28 & 0.56 & 1.15 \\
\hline Setor dummies & Sim & Sim & Sim \\
\hline Adj-R ${ }^{2}$ & Não & Sim & Sim \\
\hline OBS & 38,66 & 45,73 & 46,73 \\
\hline & 1380 & 1380 & 1380 \\
\hline
\end{tabular}


A Tabela 7 estuda as conseqüências da adesão aos novos mercados da BOVESPA em relação à variável de Amihud. No que diz respeito às variáveis de controle, encontrou-se que empresas de maior porte, com maior menor volatilidade e presença no Ibovespa apresentam uma maior liquidez (vale lembrar que a variável Amihud é inversamente proporcional à liquidez).

Em relação à variável Novos Mercados, o coeficiente estimado nas colunas I e II é negativo e significativo. Isto significa que as empresas que aderiram aos novos mercados têm maior liquidez que as demais empresas transacionadas na BOVESPA. No entanto, conforme discutido anteriormente, isto não significa que essas empresas apresentam um aumento na sua liquidez. A Coluna III responde esta questão. Neste caso, encontrou-se que o efeito da variável Novos Mercados é robusto à inclusão da variável Empresas Novos Mercados. Isto confirma que as empresas que aderiram aos novos mercados apresentaram um aumento de liquidez conforme a medida de Amihud em relação ao seu nível de liquidez anterior a adesão.

A Tabela 8 estuda as conseqüências da adesão aos novos mercados da BOVESPA em relação à variável de Volume. Neste caso os resultados são bem semelhantes aos resultados obtidos com as variáveis de Zero Retorno e Zero Volume. Isto é, o coeficiente estimado para a variável Novos Mercados nas colunas I e II é negativo e significativo. Isto significa que as empresas que aderiram aos novos mercados são mais negociadas que as demais empresas transacionadas na BOVESPA. No entanto, este efeito perde significância estatística na Coluna III, sugerindo que apesar das empresas transacionadas no novo mercado serem mais negociadas, o aumento de negociação quando comparado ao volume negociado de cada empresa antes da adesão não é significativo. 
Tabela 7

Consequiências da adesão aos novos mercados - Amihud

Esta tabela apresenta as consequiências da adesão aos Novos Mercados da BOVESPA. A variável dependente é Amihud. O modelo estimado é o modelo de mínimos quadrados ordinários (MQO). Amihud ${ }_{t+1}-\mathrm{O}$ logaritmo da mediana do price impact diário onde price impact diário é o valor absoluto do retorno diário dividido pelo volume diário. Novos Mercados - Variável dummy classificada como 1 se a empresa fazia parte de um dos novos mercados da BOVESPA (Novo Mercado, Nível 1, e Nível 2) durante o ano e 0 caso contrário. Empresas Novos Mercados - Variável dummy classificada como 1 para empresas que aderiram aos Novos Mercados durante o ano e 0 caso contrário. LOG (Ativo Total) - Logaritmo do ativo total das empresas listadas na BOVESPA. Volatilidade - Desvio padrão dos retornos diários da ação durante o ano. Ibovespa - Variável dummy classificada como 1 se a empresa fazia parte do índice Ibovespa durante o ano e 0 caso contrário. $A D R$ - Variável dummy classificada como 1 se a empresa possuía ADRs negociadas na NYSE durante o ano e 0 caso contrário.

\begin{tabular}{|c|c|c|c|}
\hline & \multicolumn{3}{|c|}{ Amihud $_{t+1}$} \\
\hline & $\bar{I}$ & II & III \\
\hline \multirow[t]{2}{*}{ Intercepto } & 11,86 & 13,22 & 12,83 \\
\hline & 8,60 & 9,80 & 9,36 \\
\hline \multirow[t]{2}{*}{ Novos Mercados } & $-2,02$ & $-1,93$ & $-0,8$ \\
\hline & $-5,69$ & $-5,55$ & $-2,29$ \\
\hline \multirow[t]{2}{*}{ Empresas Novos Mercados } & & & $-1,44$ \\
\hline & & & $-3,56$ \\
\hline \multirow[t]{2}{*}{ LOG (Ativo Total) } & $-0,91$ & $-1,05$ & -1 \\
\hline & $-8,68$ & $-10,02$ & $-9,18$ \\
\hline \multirow[t]{2}{*}{ Volatilidade } & 21,34 & 17,85 & 16,96 \\
\hline & 6,79 & 5,43 & 5,19 \\
\hline \multirow[t]{2}{*}{ Ibovespa } & $-2,87$ & $-2,39$ & $-2,51$ \\
\hline & $-6,35$ & $-5,91$ & $-6,12$ \\
\hline \multirow[t]{2}{*}{ ADR } & $-0,51$ & $-0,31$ & 0,03 \\
\hline & $-1,08$ & $-0,59$ & 0,05 \\
\hline Ano dummies & Sim & Sim & Sim \\
\hline Setor dummies & Não & Sim & Sim \\
\hline Adj-R ${ }^{2}$ & 70,74 & 76,85 & 77,5 \\
\hline OBS & 786 & 786 & 786 \\
\hline
\end{tabular}


Tabela 8

Conseqüências da adesão aos novos mercado - volume

Esta tabela apresenta as conseqüências da adesão aos Novos Mercados da BOVESPA. A variável dependente é Volume $_{t+1}$. O modelo estimado é o modelo de mínimos quadrados ordinários (MQO). Volume $_{t+1}$ - Volume em Reais ( $\mathrm{R} \$$ ) negociado durante o ano e multiplicado por menos um. Novos Mercados - Variável dummy classificada como 1 se a empresa fazia parte de um dos novos mercados da BOVESPA (Novo Mercado, Nível 1, e Nível 2) durante o ano e 0 caso contrário. Empresas Novos Mercados - Variável dummy classificada como 1 para empresas que aderiram aos Novos Mercados durante o ano e 0 caso contrário. LOG (Ativo Total) - Logaritmo do ativo total das empresas listadas na BOVESPA. Volatilidade - Desvio padrão dos retornos diários da ação durante o ano. Ibovespa - Variável dummy classificada como 1 se a empresa fazia parte do índice Ibovespa durante o ano e 0 caso contrário. $A D R$ - Variável dummy classificada como 1 se a empresa possuía ADRs negociadas na NYSE durante o ano e 0 caso contrário.

\begin{tabular}{l|c|c|c}
\hline & \multicolumn{3}{|c}{ Volume $_{t+1}$} \\
\hline & I & II & III \\
\hline Intercepto & 0.55 & 4.50 & 3.81 \\
\hline & 0.27 & 2.02 & 1.73 \\
\hline Novos Mercados & & & \\
\hline & -3.02 & -2.91 & -0.81 \\
\hline & -3.98 & -4.01 & -1.11 \\
\hline Empresas Novos Mercados & & & \\
\hline & & & -2.59 \\
\hline & & & -3.25 \\
\hline LOG (Ativo Total) & & & \\
\hline & -1.19 & -1.58 & -1.50 \\
\hline Volatilidade & -7.40 & -9.31 & -8.78 \\
\hline & & & \\
\hline & 13.51 & 10.46 & 10.31 \\
\hline Ibovespa & 3.87 & 3.24 & 3.24 \\
\hline & & & \\
\hline & -3.44 & -3.17 & -3.23 \\
\hline ADR & -4.24 & -3.99 & -4.10 \\
\hline & & & \\
\hline Ano dummies & -1.00 & -0.04 & 0.57 \\
\hline Setor dummies & -0.84 & -0.03 & 0.45 \\
\hline Adj-R ${ }^{2}$ & Sim & Sim & Sim \\
\hline OBS & Não & Sim & Sim \\
\hline & 45,14 & 55 & 55.77 \\
\hline & 1340 & 1340 & 1340 \\
\hline & & &
\end{tabular}

Uma limitação dos testes das tabelas 5 a 8 é que eles estudam o efeito da adesão aos novos mercados sem fazer a distinção entre os mercados. No entanto, conforme descrito na Seção 2, os diferentes mercados da BOVESPA apresentam regras distintas e é possível que as conseqüências da adesão sejam também distintas. Além disso, os resultados sugerem que o aumento na liquidez só é significativo quando utilizou-se a variável de Amihud podendo ser um motivo para essa 
diferença a não distinção dos diferentes mercados. Dessa forma, a Tabela 9 reavalia as conseqüências da adesão aos novos mercados da BOVESPA em relação às variáveis de liquidez. A maior diferença entre as tabelas apresentadas até então e a tabela 9 é que se incluiu variáveis dummies para cada mercado, o que permite estudar as consequiências da adesão para cada mercado separadamente.

A Tabela 9 - Painel A apresenta os resultados com as variáveis Zero Retorno e Zero Volume como medidas de liquidez. Nas primeiras duas colunas a variável dependente é Zero Retorno, enquanto que nas duas colunas seguintes a variável dependente é Zero Volume. Com relação à variável Zero Retorno, encontrou-se na Coluna I que o efeito da adesão é crescente nos níveis adotados pelas empresas na BOVESPA. Isto é, o coeficiente estimado para a variável Nível 1 é igual a -0,12, enquanto que o coeficiente das variáveis Nível 2 e Novo Mercado são iguais a $-0,25$ e $-0,37$, respectivamente. Isto significa que as empresas que aderiram ao Nível 1 apresentam 12\% menos dias sem retornos dos seus papéis do que as empresas negociadas no mercado tradicional da BOVESPA. Por outro lado, empresas que aderiram ao Novo Mercado (Nível 2) da BOVESPA apresentam 37\% (25\%) menos de dias sem negociação. A coluna II apresenta estes resultados após controlar para o nível de negociação anterior à adesão, o que permite medir o aumento na liquidez. Neste caso, encontrou-se que as empresas que aderiram ao Nível 1 sofreram uma redução de liquidez enquanto que as empresas que aderiram ao Nível 2 e ao Novo Mercado sofreram um aumento de liquidez nos seus papéis. A redução na liquidez dos papéis das empresas listadas no Nível 1 deve-se ao fato destas empresas já apresentarem altos níveis de liquidez antes da adesão. Por exemplo, o coeficiente da variável Empresa Nivel 1 é negativo e significativo, o que sugere que estas empresas apresentavam maior liquidez antes mesmo da adesão.

As colunas III e IV apresentam os resultados utilizando como variável dependente Zero Volume. Os resultados encontrados são semelhantes aos resultados utilizando Zero Retorno. Encontrou-se um efeito da adesão crescente nos níveis adotados pelas empresas na BOVESPA. Por exemplo, o coeficiente estimado para a variável Nivel 1 é igual a -0,14, enquanto que os coeficientes das variáveis Nivel 2 e Novo Mercado são iguais a -0,24 e -0,40, respectivamente. Estes resultados reforçam que as empresas que aderiram aos novos mercados apresentam maior liquidez de suas ações que as empresas negociadas no mercado tradicional da BOVESPA. A coluna IV apresenta estes resultados após controlar para o nível de liquidez anterior à adesão. Neste caso, como no caso anterior, as empresas do Nível 1 apresentaram uma redução de liquidez. Além disso, as empresas do Nível 2 e do Novo Mercado aumentaram a sua liquidez porém o efeito só é significativo pras empresas no Novo Mercado.

A Tabela 9 - Painel B apresenta os resultados com as variáveis Amihud e Volume como medidas de liquidez. Os resultados encontrados são semelhantes. Por exemplo, nas colunas I e III, pode-se inferir um efeito da adesão crescente nos níveis adotados pelas empresas na BOVESPA. Por exemplo, na coluna I, o coeficiente estimado para a variável Nível 1 é igual a -1,24, enquanto que o coeficiente 
das variáveis Nível 2 e Novo Mercado são iguais a -3,05 e -3,68, respectivamente. Estes resultados reforçam que as empresas que aderiram aos novos mercados apresentam maior liquidez segundo a medida de Amihud. Da mesma forma, na coluna III quando a variável dependente é Volume, o coeficiente estimado para a variável Nivel 1 é igual a -1,59, enquanto que o coeficiente das variáveis Nível 2 e Novo Mercado são iguais a $-5,82$ e -6,06, respectivamente. No entanto, após controlar para o nível de liquidez anterior à adesão (colunas II e IV), apenas a adesão ao Nível 2 e ao Novo Mercado permanecem com aumento de liquidez.

Tabela 9

Conseqüências da adesão aos novos mercados

\begin{tabular}{|c|c|c|c|c|}
\hline $\begin{array}{l}\text { Esta tabela apresenta as c } \\
\text { da BOVESPA. As variáv } \\
\text { lume, Amihud e Volume. } \\
\text { quadrados ordinários (M } \\
\text { nos diários igual a zero d } \\
\text { dias sem negociação dura } \\
\text { diana do price impact diá } \\
\text { do retorno diário dividid } \\
\text { em Reais (R\$) negociado } \\
\text { Nível } 1 \text { - Variável dumm } \\
\text { do Nível } 1 \text { durante o ano } \\
\text { classificada como } 1 \text { se a } \\
\text { e } 0 \text { caso contrário. Novo } \\
1 \text { se a empresa fazia par } \\
\text { contrário. Empresa Nível } \\
\text { empresas que aderiram a } \\
\text { Empresa Nível } 2 \text { - Variáv } \\
\text { que aderiram ao Nível } 2 \\
\text { Novo Mercado - Variáve } \\
\text { que aderiram ao Novo M }\end{array}$ & $\begin{array}{l}\text { Iseqüênc } \\
\text { s depen } \\
\text { modelc } \\
\text { D). Zero } \\
\text { ante o ar } \\
\text { e o ano. } \\
\text { onde } p \\
\text { pelo vol } \\
\text { urante o } \\
\text { lassifica } \\
\text { c caso c } \\
\text { apresa fe } \\
\text { rcado - } \\
\text { do Nov } \\
\text { - Variáv } \\
\text { Nível } 1 \\
\text { dummy } \\
\text { urante o } \\
\text { dummy } \\
\text { ado dur }\end{array}$ & $\begin{array}{l}\text { da ade } \\
\text { tes são } \\
\text { timado } \\
\text { torno }_{t+} \\
\text { Zero Vc } \\
\text { nihud } t+ \\
\text { impact } \\
\text { e diário } \\
\text { o e mul } \\
\text { como } 1 \\
\text { rário. } N \\
\text { parte } \\
\text { riável d } \\
\text { lercado } \\
\text { lummy } \\
\text { rante o } \\
\text { ssificad } \\
\text { o e } 0 \text { c } \\
\text { ssificad } \\
\text { e o ano }\end{array}$ & $\begin{array}{l}\text { aos } \mathrm{N} \\
\text { ro Ret } \\
\text { mode } \\
\text { - Perce } \\
\text { met+1 } \\
\text { - O lo } \\
\text { ário é o } \\
\text { Volume } \\
\text { licado } \\
\text { a emp } \\
\text { l2 - V } \\
\text { Nível } 2 \\
\text { my cla } \\
\text { Irante } \\
\text { ssifica } \\
\text { o e } 0 \\
\text { omo } 1 \\
\text { contr } \\
\text { omo } 1 \\
\text { caso c } \\
\end{array}$ & $\begin{array}{l}\text { Mercados } \\
\text { Zero Vo- } \\
\text { mínimos } \\
\text { de retor- } \\
\text { entual de } \\
\text { lo da me- } \\
\text { absoluto } \\
\text { - Volume } \\
\text { enos um. } \\
\text { azia parte } \\
1 \text { dummy } \\
\text { nte o ano } \\
\text { ada como } \\
\text { e } 0 \text { caso } \\
\text { no } 1 \text { para } \\
\text { contrário. } \\
\text { empresas } \\
\text { Empresa } \\
\text { empresas } \\
\text { rio. }\end{array}$ \\
\hline Painel A - zero retorno e & ro volun & & & \\
\hline & Zero R & $\mathrm{no}_{t+1}$ & Zerc & $\mathrm{me}_{t+1}$ \\
\hline & $\mathrm{I}$ & II & III & IV \\
\hline Intercepto & $\begin{array}{l}1,72 \\
13,74\end{array}$ & $\begin{array}{l}1,68 \\
13,72\end{array}$ & $\begin{array}{l}1.37 \\
9.48\end{array}$ & $\begin{array}{l}1.31 \\
9.36\end{array}$ \\
\hline Nível 1 & $\begin{array}{l}-0,12 \\
-2,14\end{array}$ & $\begin{array}{l}0,1 \\
1,97\end{array}$ & $\begin{array}{l}-0.14 \\
-2.36\end{array}$ & $\begin{array}{l}0.11 \\
1.95\end{array}$ \\
\hline Nível 2 & $\begin{array}{l}-0,25 \\
-3,87\end{array}$ & $\begin{array}{l}-0,2 \\
-1,9\end{array}$ & $\begin{array}{l}-0.24 \\
-2.68\end{array}$ & $\begin{array}{l}-0.19 \\
-1.44\end{array}$ \\
\hline Novo Mercado & $\begin{array}{l}-0,37 \\
-6,04\end{array}$ & $\begin{array}{l}-0,48 \\
-4,14\end{array}$ & $\begin{array}{l}-0.40 \\
-5.82\end{array}$ & $\begin{array}{l}-0.51 \\
-4.45\end{array}$ \\
\hline Empresa Nível 1 & & $\begin{array}{l}-0,26 \\
-5,23\end{array}$ & & $\begin{array}{l}-0.30 \\
-4.76\end{array}$ \\
\hline Empresa Nível 2 & & $\begin{array}{l}-0,08 \\
-1,02\end{array}$ & & $\begin{array}{c}-0.08 \\
-0.69\end{array}$ \\
\hline Empresa Novo Mercado & & $\begin{array}{l}0,09 \\
1,02\end{array}$ & & $\begin{array}{l}0.09 \\
1.06\end{array}$ \\
\hline Variáveis de Controle & Sim & Sim & Sim & Sim \\
\hline Ano dummies & Sim & Sim & Sim & Sim \\
\hline Setor dummies & Sim & Sim & Sim & Sim \\
\hline Adj-R ${ }^{2}$ & 54,56 & 55,81 & 46,32 & 48,15 \\
\hline OBS & 1380 & 1380 & 1380 & 1380 \\
\hline
\end{tabular}


Painel B - Amihud e volume

\begin{tabular}{l|c|c|c|c}
\hline & \multicolumn{2}{|c|}{ Amihud $_{t+1}$} & \multicolumn{2}{c}{ Volume $_{t+1}$} \\
\hline Intercepto & I & II & III & IV \\
\hline Nível 1 & 13,58 & 13,22 & 5.11 & 4.39 \\
& 10,08 & 9,64 & 2.28 & 1.99 \\
\hline Nível 2 & $-1,24$ & $-0,3$ & -1.59 & 0.88 \\
& $-3,3$ & $-0,74$ & -1.91 & 1.34 \\
\hline Novo Mercado & $-3,05$ & $-1,58$ & -5.82 & -4.02 \\
& -5 & $-2,04$ & -4.35 & -2.41 \\
\hline Empresa Nível 1 & $-3,68$ & $-2,82$ & -6.06 & -5.17 \\
& $-5,45$ & $-3,66$ & -3.29 & -1.97 \\
\hline Empresa Nível 2 & & $-1,26$ & & -3.01 \\
& & $-2,5$ & & -3.39 \\
\hline Empresa Novo Mercado & & $-1,8$ & & -2.26 \\
& & $-2,8$ & & -1.64 \\
\hline Variáveis de Controle & Sim & $-1,09$ & & -1.29 \\
\hline Ano dummies & Sim & Sim & Sim & Sim \\
\hline Setor dummies & Sim & Sim & Sim & Sim \\
\hline Adj-R2 & 77,71 & 78,31 & 56,01 & 56,8 \\
\hline OBS & 786 & 786 & 1340 & 1340 \\
\hline
\end{tabular}

Em geral, os resultados da tabela 9 confirmaram os resultados das tabelas $5 \mathrm{e}$ 8 de que as empresas que aderiram aos novos mercados da BOVESPA apresentam maior liquidez que as empresas transacionadas no mercado tradicional. No entanto, encontrou-se evidência de que apenas as empresas que aderiram ao Nível 2 e ao Novo Mercado experimentaram um aumento de liquidez e que as empresas que aderiram ao Nível 1 apresentaram níveis semelhantes (e em algumas vezes menores) de liquidez após a adesão.

\section{Conclusão}

Este artigo estuda os determinantes e as consequiências da adesão de empresas brasileiras aos novos mercados da BOVESPA: Novo Mercado, Nível 1 e Nível 2. Desde 2001 mais de 61 empresas passaram a serem transacionadas nestes mercados com o objetivo de melhorar suas valorizações e tendo, como conseqüência, que adotar maiores níveis de disclosure e de governança corporativa. Empresas listadas nesses segmentos oferecem aos seus investidores melhores práticas de governança corporativa. A premissa básica é que a adoção de boas práticas de governança corporativa pelas companhias confere maior credibilidade ao mercado acionário e, como conseqüência, aumenta a confiança e a disposição dos investidores em adquirirem as suas ações, pagarem um preço melhor por elas, reduzindo seu custo de captação de recursos.

No que diz respeito aos determinantes da adesão aos novos mercados, encontrou-se que as empresas que aderem se caracterizam por terem maior tamanho, maior lucratividade, maior dispersão acionária e a presença de ADR na empresa. No entanto, o efeito do endividamento e do crescimento das vendas em poucas vezes apresentou significância estatística. No que diz respeito às consequiências 
da adesão, encontrou-se que as empresas que aderiram aos novos mercados da BOVESPA apresentam maior liquidez que as empresas transacionadas no mercado tradicional. Além disso, as empresas que aderiram ao Nível 2 e ao Novo Mercado apresentaram um aumento de liquidez em relação ao nível de liquidez anterior à adesão.

Os resultados contribuem para a literatura de disclosure e de governança ao promoverem evidência de que as empresas que aderiram aos novos mercados são recompensadas com maiores níveis de liquidez nos seus papéis. Uma questão em aberto é porque mais empresas não aderem aos mercados de forma a beneficiaremse com uma maior liquidez de suas ações. Conforme discutido em Leuz e Verrecchia (2000) e Doidge et alii (2004), a decisão de adesão representa um trade-off da empresa entre os benefícios e os custos da adesão. O nosso artigo contribui para esta literatura ao evidenciar que um dos benefícios se dá por meio da liquidez dos papéis da empresa.

\section{Referências}

Amihud, Y. (2002). Illiquidity and stock returns. Journal of Financial Markets, $5: 31-56$.

Ashbaugh-Skaife, H., Gassen, J., \& Lafond, R. (2006). Does stock price synchronicity represent firm-specific information? The international evidence. Working paper.

Bekaert, G., Harvey, C. R., \& Lundblad, C. (2007). Liquidity and expected returns: Lessons from emerging markets. Review of Financial Studies, 20(6):1783-1831.

Benos, E. \& Weisbach, M. (2004). Private benefits and cross-listings in the United States. Emerging Markets Review, (forthcoming).

Brennan, M. \& Subrahmanyam, A. (1996). Market microstructure and asset pricing: On the compensation for illiquidity in stock returns. Journal of Financial Economics, July:441-464.

Copeland, T. \& Galai, D. (1983). Information effects on the bid-ask spread. Journal of Finance, (December):1457-1469.

Daske, H., Hail, L., Leuz, C., \& Verdi, R. (2007). Adopting a label: Heterogeneity in the economic consequences of IFRS adoptions. Working paper.

De Carvalho, G. (2003). Efeitos da migração para os níveis de governança da Bovespa. Working paper USP.

De Carvalho, G. \& Pennacchi, G. (2007). Can voluntary market reforms promote efficient corporate governance? Evidence from firms' migration to premium markets in Brazil. Working paper USP. 
Diamond, D. \& Verrecchia, R. (1991). Disclosure, liquidity, and the cost of capital. Journal of Finance, 46(4):1325-1359.

Doidge, C. (2003). U.S. cross-listings and the private benefits of control: Evidence from dual-class firms. Journal of Financial Economics, (forthcoming).

Doidge, C., Karolyi, A., \& Stulz, R. (2004). Why are foreign firms that are listed in the U.S. worth more? Journal of Financial Economics, 71:205-238.

Foster, F. D. \& Viswanathan, S. (1993). Variations in trading volume, return volatility, and trading costs: Evidence on recent price formation models. Journal of Finance, 48:187-211.

Glosten, L. \& Milgrom, P. (1985). Bid, ask, and transaction prices in a specialist market with heterogeneously informed traders. Journal of Financial Economics, (March):71-100.

Hail, L. \& Leuz, C. (2006). Cost of capital effects and changes in growth expectations around U.S. cross-listings. University of Pennsylvania and University of Chicago, Working paper.

Jones, C. M. (2002). A century of stock market liquidity and trading costs. Working paper. Columbia University.

Karolyi, G. A. (2003). The role of ADRs in the development and integration of emerging equity markets. Unpublished working paper, The Ohio State University.

Kyle, A. S. (1985). Continuous auctions and insider trading. Econometrica, 53:1315-1335.

Lang, M. \& Lundholm, R. (1993). Cross-sectional determinants of analyst ratings of corporate disclosures. Journal of Accounting Research, (Autumn):246-271.

Larcker, D. \& Rusticus, T. (2007). On the use of instrumental variables in accounting research. Working Paper, Stanford University.

Lee, C. M. C., Mucklow, B., \& Ready, M. J. (1993). Spreads, depths, and the impact of earnings information: An intraday analysis. Review of Financial Studies, $6: 345-374$.

Lesmond, D., Ogden, J., \& Trzcinka, C. (1999). A new estimate of transaction costs. The Review of Financial Studies, 12:1113-1141.

Leuz, C. (1999). Voluntary disclosure of cash flow statements and business segment data in Germany. Working paper, University of Pennsylvania.

Leuz, C. \& Verrecchia, R. (2000). The economic consequences of increased disclosure. Journal of Accounting Research, 38:91-124. 
Pastor, L. \& Stambaugh, R. (2003). Liquidity risk and expected stock returns. Journal of Political Economy, 111:642-685.

Petersen, M. (2008). Estimating standard errors in finance panel data sets: Comparing approaches. Review of Financial Studies, forthcoming.

Silveira, A., Barros, L., \& Fama, R. (2004). Determinants of corporate governance quality of Brazilian listed companies. IV Meeting of the Brazilian Finance Society, Rio de Janeiro, July.

Silveira, A., Leal, R., Carvalhal Da Silva, A., \& Barros, L. (2007). Evolution and determinants of firm-level corporate governance quality in Brazil. Working paper USP.

Verrecchia, R. E. (2001). Essays on disclosure. Journal of Accounting \& Economics, 32:91-180. 


\section{Apêndice 1}

\section{Comparação entre os Mercados da BOVESPA}

\begin{tabular}{|c|c|c|c|c|}
\hline & Novo mercado & Nível 2 & Nível 1 & Tradicional \\
\hline $\begin{array}{ll}\text { Percentual } & \\
\text { Mínimo de } & \text { em } \\
\text { Ações } & \text { em } \\
\text { Circulação } & \\
\text { (free float) } & \end{array}$ & $\begin{array}{l}\text { No mínimo } 25 \% \text { de } \\
\text { free float }\end{array}$ & $\begin{array}{l}\text { No mínimo } 25 \% \text { de } \\
\text { free float }\end{array}$ & $\begin{array}{l}\text { No mínimo } 25 \% \text { de } \\
\text { free float }\end{array}$ & Não há regra \\
\hline $\begin{array}{l}\text { Características } \\
\text { das Ações } \\
\text { Emitidas }\end{array}$ & $\begin{array}{l}\text { Permite a existência } \\
\text { somente de ações } \\
\text { ON }\end{array}$ & $\begin{array}{l}\text { Permite a existência } \\
\text { de ações ON e PN } \\
\text { (com direitos adici- } \\
\text { onais) }\end{array}$ & $\begin{array}{l}\text { Permite a existência } \\
\text { de ações ON e PN }\end{array}$ & $\begin{array}{lr}\text { Permite } & \text { a } \\
\text { existência de } \\
\text { ações ON e PN }\end{array}$ \\
\hline $\begin{array}{l}\text { Conselho de } \\
\text { Administração }\end{array}$ & $\begin{array}{l}\text { Mínimo de cinco } \\
\text { membros, dos quais } \\
\text { pelo menos } 20 \% \text { de- } \\
\text { vem ser indepen- } \\
\text { dentes }\end{array}$ & $\begin{array}{l}\text { Mínimo de cinco } \\
\text { membros, dos quais } \\
\text { pelo menos } 20 \% \text { de- } \\
\text { vem ser indepen- } \\
\text { dentes }\end{array}$ & $\begin{array}{l}\text { Mínimo de três } \\
\text { membros (conforme } \\
\text { legislação) }\end{array}$ & $\begin{array}{l}\text { Mínimo de } \\
\text { três membros } \\
\text { (conforme } \\
\text { legislação) }\end{array}$ \\
\hline $\begin{array}{l}\text { Demonstrações } \\
\text { Financeiras } \\
\text { Anuais em } \\
\text { Padrão Inter- } \\
\text { nacional }\end{array}$ & US GAAP ou IFRS & US GAAP ou IFRS & Facultativo & Facultativo \\
\hline $\begin{array}{ll}\text { Concessão } & \text { de } \\
\text { Tag Along } & \end{array}$ & $\begin{array}{lll}100 \% & \text { para } & \text { ações } \\
\text { ON } & & \end{array}$ & $\begin{array}{l}100 \% \text { para ações } \\
\text { ON } 80 \% \text { para ações } \\
\text { PN }\end{array}$ & $\begin{array}{l}80 \% \text { para ações } \\
\text { ON (conforme } \\
\text { legislação) }\end{array}$ & $\begin{array}{lr}80 \% & \text { para } \\
\text { ações } & \text { ON } \\
\text { (conforme } & \\
\text { legislação) } & \end{array}$ \\
\hline $\begin{array}{ll}\text { Adoção } & \text { da } \\
\text { Câmara } & \text { de } \\
\text { Arbitragem } & \text { do } \\
\text { Mercado } & \end{array}$ & Obrigatório & Obrigatório & Facultativo & Facultativo \\
\hline
\end{tabular}


Apêndice 2

Lista de Empresas nos Novos Mercados da BOVESPA

\begin{tabular}{|c|c|c|c|}
\hline \multicolumn{4}{|c|}{ Painel A - empresas listadas no nível 1} \\
\hline Empresa & Ano de Adesão & Empresa & Ano de Adesão \\
\hline Alpargatas & 2003 & Iochpe Maxion & 2005 \\
\hline Aracruz Celulose & 2002 & Itausa & 2001 \\
\hline Arcelor Brasil & 2005 & Klabin & 2002 \\
\hline Bco Itaú & 2001 & Mangels & 2003 \\
\hline Bradesco & 2001 & Pão-de-açúcar & 2003 \\
\hline Bradespar & 2001 & Randon Partic & 2001 \\
\hline BrasilTelecom Part & 2002 & Sadia & 2001 \\
\hline BrasilTelecom & 2002 & Suzano Papel & 2004 \\
\hline Braskem & 2003 & Transmissão Paulista & 2002 \\
\hline Cia de Fiação - Cedro & 2003 & Ultrapar & 2005 \\
\hline Cemig & 2001 & Unibanco & 2001 \\
\hline Cia Hering & 2002 & Unibanco Holding & 2001 \\
\hline Confab & 2003 & Unipar & 2004 \\
\hline Duratex & 2005 & Vale & 2003 \\
\hline Fras-le & 2004 & Vigor & 2001 \\
\hline Gerdau S.A. & 2001 & Votorantin & 2001 \\
\hline Gerdau Met & 2003 & Weg & 2001 \\
\hline
\end{tabular}

\begin{tabular}{l|c}
\hline \multicolumn{1}{c}{ Painel B - empresas listadas no nível 2 } \\
\hline ALL & Ano de Adesão \\
\hline Celesc & 2004 \\
\hline Eletropaulo Metropolitana & 2002 \\
\hline Eternit & 2004 \\
\hline Gol & 2005 \\
\hline Marcopolo & 2004 \\
\hline NET & 2002 \\
\hline Suzano Petroquímica & 2002 \\
\hline TAM & 2004 \\
\hline Universo Online & 2005 \\
\hline
\end{tabular}

\begin{tabular}{|c|c|c|c|}
\hline \multicolumn{4}{|c|}{ Painel C-empresas listadas no novo mercado } \\
\hline Empresa & Ano de Adesão & Empresa & Ano de Adesão \\
\hline CCR Rodovias & 2002 & Natura & 2004 \\
\hline Cosan Ind. Com. & 2005 & Nossa Caixa & 2005 \\
\hline CPFL Energia & 2004 & OHL Brasil & 2005 \\
\hline Cyrela Realty & 2005 & Porto Seguro & 2004 \\
\hline Dasa - Diagnósticos da América & 2004 & Renar Maças & 2005 \\
\hline Energias BR & 2005 & Sabesp & 2002 \\
\hline Grendene & 2004 & Submarino & 2005 \\
\hline Localiza & 2005 & Tractebel & 2005 \\
\hline Lojas Renner & 2005 & & \\
\hline
\end{tabular}

